Рощупкина Виолетта Викторовна

\title{
МЕТОДОЛОГИЧЕСКИЕ ОСНОВЫ УЧЕТА В НАЛОГОВЫХ ОРГАНАХ: СОВРЕМЕННЫЕ ФОРМЫ И НЕОБХОДИМОСТЬ МОДЕРНИЗАЦИИ В УСЛОВИЯХ ЦИФРОВИЗАЦИИ ЭКОНОМИКИ
}

В рамках исследования методологических основ учета в налоговых органах раскрыты актуальные формы учетной деятельности. Современные формы налогового учета выступают главным инструментом фискальных органов государства в прочессе администрирования и контроля. Методологические основы учета, определенные в соответствующей главе налогового кодекса, постоянио корректируются согласно требованиям новой экономической ситуации. Исследование категориально-понятийного аппарата налогового учета, формирование методико-инструментарной базы налогового учета. Применялись аналитический, сравнительный, экономико-статистический методы.

Ключевые слова: налог, учет, отчетность.

\section{Violetta Roshchupkina}

METHODOLOGICAL BASES OF ACCOUNTING IN TAX AUTHORITIES: MODERN FORMS AND THE NECESSITY OF MODERNIZATION IN THE CONDITIONS OF DIGITALIZATION OF THE ECONOMY

Modern forms of tax accounting are the main instrument of the fiscal bodies of the state in the process of administration and control. The methodological basis of accounting, defined in the relevant chapter of the tax code, is constantly being adjusted in accordance with the requirements of the new economic situation. The study of the categorical conceptual apparatus of tax accounting, the formation of the methodological and instrumental base of tax accounting. Analytical, comparative, economic and statistical methods were used.

Key words: tax, accounting, reporting.

Bведениe / Introduction. В условиях цифровой экономики внедрение информационных технологий становится одним из факторов, обеспечивающих высокую скорость принятия управленческих решений, что в свою очередь требует мгновенного получения и анализа информации из всех возможных источников. Все больше организаций представляют налоговую отчетность в электронном виде. Документооборот активно переходит в виртуальную сферу. Обмен документами (информацией) в электронном виде также способствует дальнейшей трансформации как модели ведения бизнеса и бизнес-процессов организаций, так и традиционной концепции налогового контроля [1].

Ведение информационного ресурса «Расчеты с бюджетом» местного уровня осуществляется в территориальных органах ФНС России по субъектам Российской Федерации и Межрегиональных инспекциях по крупнейшим налогоплательщикам. Ежемесячно данные информационного ресурса выгружаются на региональный уровень в вышестоящие организации для последующего формирования ряда форм статистической налоговой отчетности.

Совокупность операций по регистрации и учету налогоплательщиков, оперативно-бухгалтерскому учету и, соответственно, формированию статистической налоговой отчетности составляют учетную работу налоговых органов [2]. Из-за значительного объема обрабатываемой информации учетная работа налоговых органов является трудоемким процессом, особенно в крупных 
регионах с большим числом плательщиков. Упрощение учета может быть достигнуто путем автоматизации учетных операций, унификации форм учета и отчетности. Автоматизация учетной работы предполагает не только внедрение информационных продуктов, отвечающим современным условиям налогового контроля, но и максимальное ограничение влияния внешних факторов на ввод, обработку и анализ введенных данных [3].

Maтериалы и методы / Materials and methods. Федеральной налоговой службой Российской Федерации утверждены Отчеты о налоговых поступлениях в бюджетную систему в виде таблиц и ведомостей. Выделяют следующие основные формы отчетности налоговых органов: Форма № 1-НМ - «Отчет о поступлении налоговых платежей и других доходов в бюджетную систему Российской Федерации».

Сводные отчеты на федеральном уровне в целом по России и в разрезе субъектов Российской Федерации передаются по электронным каналам связи в адреса министерств и ведомств, в Управления Президента Российской Федерации, Совет Федерации Федерального Собрания, Аппарат Правительства РФ, Комитет Государственной Думы Российской Федерации по налогам и сборам, Министерство финансов России, Счетную палату Российской Федерации [4].

Аналитическая работа основывается на информационных ресурсах, построеных с использованием облачных технологий. Для широкого круга пользователей статистические отчетные данные размещаются на официальном Интернет-сайте ФНС России и на государственных порталах. Вся отчетность используется органами власти для формирования налоговой политики Российской Федерации; расчетов и обоснований предложений по изменению налогового законодательства; оценки влияния новых законодательных инициатив на объемы поступлений в бюджет Российской Федерации; формирования показателей социально-экономического развития Российской Федерации и субъектов Российской Федерации; прогнозирования бюджетов всех уровней; оценки бюджетной обеспеченности субъектов в целях предоставления субсидий и дотаций; анализа эффективности налоговых льгот [5]. На региональном и местном уровнях также осуществляется работа по предоставлению отчетных данных органам исполнительной власти субъектов Российской Федерации и администрациям муниципальных образований. Предусмотрено предоставление информации о налоговой базе и структуре начислений по налогам и сборам, зачисляемым в местный бюджет, - это отчеты по формам статистической налоговой отчетности с индексом «5», а также сведений о начислении, поступлении и задолженности, которые передаются в виде информационного массива [6].

Очевидно, что данные статистической отчетности должны соответствовать следующим требованиям: достоверность; полнота; сопоставимость (единообразие) данных; своевременность формирования [7].

Исходя из поставленных целей и задач в налоговой службе характерно применение следующих методов анализа налоговых поступлений:

1. Метод сравнений (сопоставлений).

Применяется для определения уровня собираемости налогов или исполнения налоговых обязательств (т. е. сравнительный анализ фактических поступлений с начисленными), изучения тенденций начисленных и уплаченных сумм налогов путем расчета темпов роста (темпов прироста).

2. Изучение структуры налоговых поступлений по уровням бюджетной системы предполагает метод структурного исследования. Также возможно исследование состава налоговых поступлений, начислений и задолженности по видам экономической деятельности, в разрезе плательщиков (юридические лица, индивидуальные предприниматели, физические лица).

3. Метод факторного анализа. 
Выявляет текущую динамику налоговых поступлений исходя из текущих макроэкономических параметров, причины изменения объема налоговых поступлений по сравнению с базовым периодом по факторам, определившим это изменение.

4. Метод использования интегральных показателей.

Используется для расчета налоговой нагрузки как процентное отношение налоговых поступлений (начислений) к валовому региональному продукту или определения уровня налогового риска как оценки вероятности занижения налогоплательщиком налоговых баз.

5. Метод группировок [8]

В ходе анализа проводится группировка показателей по различным признакам, например, по территориальным (в разрезе УФНС, ИФНС), по видам деятельности или категории налогоплательщиков [9].

В целях объективного отражения ситуации анализ показателей проводится как в абсолютном, так и относительном выражении по следующим направлениям:

- определение уровня собираемости налоговых поступлений в отчетном периоде, сравнение с показателем аналогичного периода предыдущего года;

- изменение задолженности в течение отчетного периода, анализ причин выявленной динамики;

- анализ налоговой нагрузки [10].

Согласно нашей точке зрения, для объективного отражения налоговых поступлений необходимы не только результаты анализа данных форм ведомственной отчетности, но и показатели социально-экономического развития страны, региона, которые оказывают влияние на поступление налогов и сборов в консолидированный бюджет [11]. Для этого используются данные государственной статистики по таким показателям как внутренний валовый продукт (ВВП), региональный валовый продукт (РВП), уровень инфляции, фонд заработной платы, розничный товарооборот и т.д. Совокупность указанных показателей служит базой для составления аналитических записок о ходе налоговых поступлений, поиска резервов их увеличения [12]. Данное направление деятельности налоговых органов формирует блок аналитической работы.

Структура и состав аналитической записки включает разделы:

1. Экономическая ситуация.

Раздел содержит сведения об изменении объемов валового продукта (внутреннего или регионального), динамике товарооборота, индексах потребительских и оптовых цен и другое. Для составления используются данные органов статистики, налоговый паспорт.

2. Характеристика налогоплательщиков (данные об изменении числа налогоплательщиков). Для составления используются данные форм налоговой отчетности 1-УЧ, 1-ЮР, 1-ИП.

3. Анализ налогооблагаемой базы [13].

В содержании отражается комплексный анализ факторов, влияющих на формирование налогооблагаемой базы по отдельным видам налогов. Используются данные форм о налоговой базе и структуре начислений по видам налогов с индексом (5) (5-ECXН, 5-НДПИ, 5-ТН, 5-НИО и др.), а также показатели отчета по форме №1-НДС и ряд экономических показателей из отчетов органов статистики (валовая прибыль, фонд оплаты труда и другие).

4. Показатели отчета по формам: №1-НМ, №1-НОМ, №2-ЕМ, №2-МРИ, №3-МРИ участвуют в анализе поступлений налоговых платежей в бюджетную систему Российской Федерации (динамика поступлений по уровням бюджетной системы, по видам налогов, по отраслям экономики, налоговой нагрузки). 
5. На основе данных отчетов 2-ЕМ, 2-МРИ анализируется процесс выполнения задания по мобилизации налогов, контролируемых ФНС России, причин перевыполнения или недовыполнения задания.

6. По показателям ведомственной отчетности по формам 4-НМ, 4-НОМ, 4-ИН, 4-Т выполняется анализ задолженности по налоговым платежам и сборам, совокупной задолженности, прироста в абсолютном и относительном выражении, причин изменения задолженности по отраслям, в разрезе видов налогов, эффективности мер взыскания.

7. Организация контрольной работы: анализ результатов контрольной работы, динамика изменений основных показателей контрольной работы. Используются данные отчетов 1-НТК, 2-НК, 2-НM, 3-НC, 1-ККТ, 1-НГР.

8. Предложения по увеличению собираемости налоговых платежей [14].

В ходе аналитической работы подробно изучается состояние налогоплательщиков, налогооблагаемой базы, задолженности по платежам, уровня собираемости налоговых поступлений. Информация аналитических записок может способствовать изменению направлений контрольных мероприятий или служить основанием для внесения изменений в действующее законодательство. Организация аналитической работы в налоговых органах позволяет определить направление налоговой политики, проводимой в субъекте Российской Федерации или государстве в целом, а также его эффективность в налоговом администрировании [15].

Основной задачей в части прогнозно-аналитической работы ФНС России являются максимальная автоматизация сбора и обработки информации и внедрение автоматизированных методов расчета аналитических показателей.

Ключевые преимущества использования информационно-аналитических систем отражены в таблице.

Таблицуа

Ключевые преимущества использования информационно-аналитических системы в налоговых органах

\begin{tabular}{|l|l|}
\hline $\begin{array}{c}\text { Наименование программно- } \\
\text { аналитичского комплекса }\end{array}$ & $\begin{array}{c}\text { Преимущества использования программно-аналитического ком- } \\
\text { плекса }\end{array}$ \\
\hline ПАК «Аналитика» & $\begin{array}{l}\text { Система обеспечивает информационную и инструментальную под- } \\
\text { держку формирования аналитических таблиц мониторинга и анализа } \\
\text { налоговых поступлений, а также социально-экономической статистики. } \\
\text { Кроме того, она позволяет провести комплексный региональный анализ } \\
\text { налоговых поступлений с учетом показателей социально-экономиче- } \\
\text { ского развития регионов, анализ данных информационных ресурсов для } \\
\text { планирования поступлений адмнистрируемых доходов по видам нало- } \\
\text { гов в разрезе субъектов РФ, управлений ФНС России и межрегиональ- } \\
\text { ных инспекций ФНС России по крупнейшим налогоплательщикам [16]. } \\
\text { Вместе с тем в данном комплексе реализована возможность формиро- } \\
\text { вания многофакторных динамических моделей налоговой базы и нало- } \\
\text { говых поступлений, выполнения многовариантных расчетов комплек- } \\
\text { са взаимосвязанных моделей, сценарного прогнозирования налоговой } \\
\text { базы и налоговых поступлений, визуализации полученных результатов } \\
\text { в табличном, графическом и картографическом видах [17]. }\end{array}$ \\
\hline Рабочее место Руководителя & $\begin{array}{l}\text { Система «Рабочее место Руководителя» представляет собой веб-стра- } \\
\text { ницу с настраиваемыми критическими индикаторами, состоящую из } \\
\text { нескольких блоков и подразделов. Блоки и подразделы предоставляют } \\
\text { оперативный доступ к сводной информации о динамике и структуре } \\
\text { налоговых поступлений по видам налогов и сборов (с возможностью } \\
\text { группировки) по уровням бюджетов РФ, о задолженности и недоимке } \\
\text { в оонсолидированный бюджет РФ, а также о результатах контрольных } \\
\text { налоговых проверок и доначисленных суммах. Кроме того, в системе } \\
\text { доступна информация в разрезе субъектов РФ по всем направлениям }\end{array}$ \\
\hline
\end{tabular}




\begin{tabular}{|l|l|}
\hline $\begin{array}{c}\text { Наименование программно- } \\
\text { аналитического комплекса }\end{array}$ & \multicolumn{1}{|c|}{$\begin{array}{c}\text { Преимушества использования программно-аналитического ком- } \\
\text { плекса }\end{array}$} \\
\hline & $\begin{array}{l}\text { налогового администрирования и реализована возможность сравни- } \\
\text { тельного анализа субъектов по нескольким показателям и формирова- } \\
\text { ния рангов [18]. Также здесь представлена актуальная информация об } \\
\text { основных макроэкономических показателях социально-экономического } \\
\text { развития РФ, международной деятельности, налоговых системах стран } \\
\text { мира и международной экономической и налоговой статистике } \\
\text { Таким образом, РМР обеспечивает комплексный анализ информации в } \\
\text { онлайн-режиме для достижения стратегических целей и эффективного } \\
\text { управления посредством оперативного принятия решений. }\end{array}$ \\
\hline
\end{tabular}

Осознавая, что сегодня от эффективности использования глобальных массивов данных в конечном счете зависит и эффективность налогового администрирования, начиная с 2010 года Служба реализует проект комплексной модернизации налоговых органов АИС «Налог-3», основанный на принципах централизованной архитектуры с максимальной автоматизацией и оптимизацией бизнес-процессов с использованием современных технологий сбора, обработки и анализа информации. Это позволит создать систему налогового администрирования, адекватную современным формам и структуре бизнеса, существенно повысить качество налогового контроля и государственных услуг, оказываемых гражданам. Реализация нового подхода налоговой службы к централизации информационных ресурсов на основе ЦОД с применением облачных технологий существенно повысит качество работы с информационными ресурсами и снизит затраты на эксплуатацию системы за счет консолидации информационных ресурсов в единой точке и применения унифицированных технологий и единых процессов управления эксплуатацией. Задача расширения состава анализируемой информации будет решена, когда в любой момент времени в аналитических целях будет доступна полная и актуальная информация из любого региона России. Все это позволит подключить интеллектуальный анализ уже на конечном этапе, когда автоматически будут определены реперные точки и проблемные места.

Автоматизация сведений первичного учета с применением современных качественных информационных продуктов проводится с целью повышения достоверности и оперативности обработки входящей информации, а также максимального ограничения влияния внешних факторов на обработку. Считаем, что на данном этапе необходимо дальнейшее совершенствование автоматизированной информационной системы АИС «Налог-3». Сейчас в системе централизованно администрируются все налоговые начисления физических лиц и индивидуальных предпринимателей, а также $25 \%$ юридических лиц по всем субъектам Российской Федерации, в ближайшее время необходимо завершить конвертацию данных по всем юридическим лицам.

Дальнейшая работа по совершенствованию форм статистической налоговой отчетности актуальна в части упрощения используемой системы показателей. Например, отмены сбора показателей, потерявших свою актуальность.

Pезультаты и обсуждение / Results and discussion. В заключение следует отметить, что использование информационно-аналитических систем как инструментов эффективного управления способствует более четкому и планомерному достижению поставленных стратегических целей, своевременному выявлению проблемных направлений и принятию оперативных мер корректирующего воздействия для улучшения эффективности работы налоговой службы.

Заключение / Conclusion. Цифровизация и интеграция всех источников информации и потоков данных в единое информационное пространство с последующей автоматизацией ее анализа на основе внедрения современных технологий обработки больших массивов данных позволит кратно расширить функции налогового администрирования. Одновременно это станет наиболее эффективным инструментом пресечения теневого бизнеса, что позволит увеличить доходную часть бюджетной системы Российской Федерации. 
Обязанностью налоговых органов является предоставление финансовым органам информации о налоговой базе и структуре начислений налогам и сборам путем составления отчетов по формам статистической налоговой отчетности, и сведений о начислении, задолженности, которые передаются в форме информационного массива. Информационный массив содержит в себе значительный объем информации, на основе которой финансовыми органами могут осуществляться любые группировки и расчеты под свои задачи при наличии технического оснащения. Таким образом, проведение анализа на основании статистических данных позволяет изучить динамику начисленных и уплаченных сумм налогов, определить их уровень и структурную характеристику, темпы роста и прироста, величину задолженности. Реализация указанных направлений позволит повысить точность налогового контроля и автоматизировать его.

\section{ЛИТЕРАТУРА И ИНТЕРНЕТ-РЕСУРСЫ}

1. Амиралиева, Д. М. Налоговое консультирование как способ борьбы с налоговыми правонарушениями // Экономика и банковская система: теория и практика : материалы заочной международной научно-практической конференции. 2016. С. 33-37.

2. Русанов, И. В., Меркулов, В. В. Роль федеральных округов в исполнении заданий по мобилизации налогов в бюджетную систему // Дневник наук, 2018. №11. // режим доступа: http://www.dnevniknauki. ru/images/publications/2018/11/economy/Merkulov_Ramazanova_Rusanov_Timchenko.pdf.

3. Баканова, К. Д., Власенко, А. Ю. Методические основы учета в налоговых органах // Дневник наук, 2018. № 11 // URL: http://www.dnevniknauki.ru/images/publications/2018/11/economy/Bakanova_ Vlasenko Karnauhova.pdf.

4. Рощупкина, В. В. Мониторинг результативности контрольной деятельности налогового органа: муниципальный уровень // Вестник СКФУ. 2018. №2. (65). С.131-137.

5. Цельникер, Г. Ф. Эффективность организации выездных налоговых проверок // Современные технологии в мировом научном пространстве : сб. ст. Международной научно-практической конференции: в 6 ч. У.фа. 2017. С.219-222.

6. Медня, Д.Ю. Особенности определения категории налоговых расходов в процессе оценки бюджетной эффективности действующих налоговых льгот субъектов Российской Федерации // Финансы и кредит. 2018. № 10 (778). С.2399-2408.

7. Меркулов, В. В., Русанов, И. В. Приоритеты совершенстования налоговой политики на региональном уровне // Материалы VII международной научно-практической конференции «Актуальные вопросы совершенствования бухгалтерского учета. статистики и налогообложения». Тамбов. 2018. С.170-177.

8. Овчар, О. В. Пути совершенствования налогового администрирования крупнейших налогоплательщиков нефтегазового сектора // Финансы и кредит. 2017. № 13 (733). С. 780-790.

9. Синегрибова, И. В. Выездные налоговые проверки: актуальные вопросы проведения и пути совершенствования // Журнал юридические исследования. 2017. Т. 2, № 2. С. 246-257.

10. Алехин, Б. И. Фискальный дисбаланс и экономический рост России // Финансовая аналитика: проблемы и решения. 2019. № 1 (347). С. 4-22.

11. Арцуев, А. М. Проблемы налоговой системы РФ и пути ее совершенствования // Е-Scio. 2017. № 4. C. 1-5.

12. Кузнецова, В. В. Основы налогового менеджмент. М.: Мир книги, 2015. 240 с.

13. Давлетшин, Т.Г. Реформирование налоговой системы России: проблемы и решения // Финансы и кредит. 2018. № 2 (770). С. 465-464.

14. Давлетшин, Т. Г. Реформирование НДС: переход на налог на товары и услуги (НТУ) и изменения в понятийном аппарате // Финансы и кредит. 2018. № 6 (774). С. 1432-1446.

15. Давлетшин, Т. Г. Собираемость НДС // Финансы и кредит. 2017. № 2 (722). С. 64-77.

16. Едронова, В. Н., Телегус, А. В. Методологические и практические проблемы формирования налоговой обязанности по налогу на доходы физических лиц, выявляемые при налоговом консультировании // Финансы и кредит. 2017. № 19 (739). С. 1108-1123.

17. Федотов, Д. Ю. Коррупция и уклонение от уплаты налогов: взаимосвязь социальных явлений // Финансы и кредит. 2018. № 19 (739). С. 2849-2862.

18. Паршина, И. В. Бюджетная классификация доходов: прошлое, настоящее и будушее // Финансы и кредит. 2018. № 4 (772). С. 845-849. 


\section{REFERENCES AND INTERNET RESOURCES}

1. Amiralieva, D. M. Nalogovoe konsul'tirovanie kak sposob bor'by s nalogovymi pravonarusheniyami (Tax consultation as way of fight against tax offenses), Ekonomika i bankovskaya sistema: teoriya i praktika: materialy zaochnoj mezhdunarodnoj nauchno-prakticheskoj konferencii. 2016. P. 33-37.

2. Rusanov, I.V., Merkulov, V.V. Rol' federal'nyh okrugov v ispolnenii zadanij po mobilizacii nalogov v byudzhetnuyu sistemu (A role of federal districts performed by tasks on mobilization of taxes in the budgetary system), Dnevnik nauk, 2018. № 11. URL: http://www.dnevniknauki.ru/images/publications/2018/11/ economy/Merkulov_Ramazanova_Rusanov_Timchenko.pdf.

3. Bakanova, K. D., Vlasenko, A.YU Metodicheskie osnovy ucheta v nalogovyh organah (Methodical bases of account in tax authorities), Dnevnik nauk, 2018. № 11. URL: http://www.dnevniknauki.ru/images/ publications/2018/11/economy/Bakanova_Vlasenko_Karnauhova.pdf.

4. Roshchupkina, V. V. Monitoring rezul'tativnosti kontrol'noj deyatel'nosti nalogovogo organa: municipal'nyj uroven' (Monitoring of effectiveness of control activity of tax authority: SKFU municipal level), Vestnik SKFU. 2018. №2. (65). P.131-137.

5. Cel'niker, G. F. Effektivnost' organizacii vyezdnyh nalogovyh proverok (Efficiency of the organization of exit tax audits), Sovremennye tekhnologii v mirovom nauchnom prostranstve : sb. st. Mezhdunarodnoj nauchno-prakticheskoj konferencii: v 6 ch. Ufa. 2017. P.219-222.

6. Mednya, D. YU. Osobennosti opredeleniya kategorii nalogovyh raskhodov v processe ocenki byudzhetnoj effektivnosti dejstvuyushchih nalogovyh l'got sub»ektov Rossijskoj Federacii (Features of determination of category of tax expenses in the course of assessment of the budgetary efficiency of the operating tax benefits of territorial subjects of the Russian Federation), Finansy i kredit. 2018. № 10 (778). P.2399-2408.

7. Merkulov, V. V., Rusanov, I. V. Prioritety sovershenstovaniya nalogovoj politiki na regional'nom urovne (Priorities of a sovershenstovaniye of tax policy at the regional level), Materialy VII mezhdunarodnoj nauchno-prakticheskoj konferencii «Aktual'nye voprosy sovershenstvovaniya buhgalterskogo ucheta. statistiki i nalogooblozheniya». Tambov, 2018. P.170-177.

8. Ovchar, O. V. Puti sovershenstvovaniya nalogovogo administrirovaniya krupnejshih nalogoplatel'shchikov neftegazovogo sektora (Ways of improvement of tax administration of the largest taxpayers of the oil and gas sector),Finansy i kredit. 2017. № 13 (733). P. 780-790.

9. Sinegribova, I. V. Vyezdnye nalogovye proverki: aktual'nye voprosy provedeniya i puti sovershenstvovaniya (Exit tax audits: topical issues of carrying out and way of improvement), Zhurnal yuridicheskie issledovaniya. 2017. T. 2, № 2. P. 246-257.

10. Alekhin, B. I. Fiskal'nyj disbalans i ekonomicheskij rost Rossii (Fiscal imbalance and economic growth of Russia), Finansovaya analitika: problemy i resheniya. 2019. № 1 (347). P. 4-22.

11. Arcuev, A. M. Problemy nalogovoj sistemy RF i puti ee sovershenstvovaniya (Problems of a tax system of the Russian Federation and way of its improvement), E-Scio. 2017. № 4. P. 1-5.

12. Kuznecova, V. V. Osnovy nalogovogo menedzhment (Bases tax management). M.: Mir knigi, 2015. 240 p.

13. Davletshin, T. G. Reformirovanie nalogovoj sistemy Rossii: problemy i resheniya (Reforming of a tax system of Russia: problems and decisions), Finansy i kredit. 2018. № 2 (770). P. 465-464.

14. Davletshin, T. G. Reformirovanie NDS: perekhod na nalog na tovary i uslugi (NTU) i izmeneniya v ponyatijnom apparate (Reforming of the VAT: transition to a tax on goods and services (NTU) and changes in a conceptual framework), Finansy i kredit. 2018. № 6 (774). P. 1432-1446.

15. Davletshin, T. G. Sobiraemost' NDS (Collecting of the VAT), Finansy i kredit. 2017. № 2 (722). P. 64-77.

16. Edronova, V.N., Telegus, A.V. Metodologicheskie i prakticheskie problemy formirovaniya nalogovoj obyazannosti po nalogu na dohody fizicheskih lic, vyyavlyaemye pri nalogovom konsul'tirovanii (The methodological and practical problems of formation of a tax obligation for an income tax revealed at tax consultation), Finansy i kredit. 2017. № 19 (739). P. 1108-1123.

17. Fedotov, D. YU. Korrupciya i uklonenie of uplaty nalogov: vzaimosvyaz' social'nyh yavlenij (Corruption and evasion of taxes: interrelation of the social phenomena). Finansy i kredit. 2018. № 19 (739). P. 2849-2862.

18. Parshina, I. V. Byudzhetnaya klassifikaciya dohodov: proshloe, nastoyashchee i budushchee (Budgetary classification of income: last, real and future), Finansy i kredit. 2018. № 4 (772). P. 845-849. 


\section{СВЕДЕНИЯ ОБ АВТОРЕ}

Рощупкина Виолетта Викторовна, доктор экономических наук, доцент, профессор кафедры «Налоговая политика и таможенное дело», Институт экономики и управления, Северо-Кавказский федеральный университет, ул. Пушкина, корпус 21, аудитория 509. E-mail: kluvil@rambler.ru

\section{INFORMATION ABOUT AUTHOR}

Roshchupkina Violetta Victorovna, Doctor of Economics, associate professor, professor of department «Tax policy and customs affairs», Institute of economy and management, North Caucasian federal university, Pushkin s., building 21, room 509. E-mail: kluvil@rambler.ru 